\title{
PERANCANGAN APLIKASI LAUNDRY PADA TIAVI LAUNDRY DEPOK BERBASIS JAVA NETBEANS
}

\author{
Rohmawaty $^{1}$, Herlinda $^{2}$, Berta Dian Theodora ${ }^{3}$ \\ Program Studi Teknik Informatika, Fakultas Teknik dan Ilmu Komputer, \\ Universitas Indraprasta PGRI \\ Jalan Raya Tengah No 80, Kelurahan Gedong, Pasar Rebo, Jakarta Timur \\ rohmawaty2608@gmail.com ${ }^{1}$,linda_said72@ymail.com ${ }^{2}$,berta.dtos@gmail.com ${ }^{3}$
}

\begin{abstract}
Abstrak
Perkembangan teknologi yang sangat pesat membuat manusia mencari inovasi baru terutama dalam bidang teknologi informasi. Salah satu bentuk manfaat teknologi informasi akan diterapkan pada Tiavi Laundry. Tujuan penelitian ini adalah untuk menggantikan sistem pada Tiavi Laundry yang masih manual menjadi terkomputerisasi. Metode penelitian yang digunakan adalah metode R\&D (Research and Development) dan teknik yang digunakan adalah metode kepustakaan. Hasil dari penelitian adalah dapat mengidentifikasi pendataan menjadi lebih mudah. Sistem yang ada pada Tiavi Laundry menjadi terkomputerisasi, rapih dalam hal penyimpanan data dan laporan, Aplikasi ini menjadikan setiap proses menjadi efektif dan dengan sistem yang terkomputerisasi masalah yang ada dapat dihindari dan meningkatkan cara kerja yang akurat.
\end{abstract}

Kata Kunci: Perancangan, Aplikasi, Laundry

\begin{abstract}
The rapid development of technology makes humans look for new innovations, especially in the field of information technology. One form of information technology benefits will be applied to Tiavi Laundry. The purpose of this study is to replace the system on Tiavi Laundry that is still manual to be computerized. The research method used is the $R \& D$ (Research and Development) method and the technique used is the literature method. The result of the study is that it can identify data collection to be easier. The existing system in Tiavi Laundry becomes computerized, neat in terms of data storage and reports, this application makes every process effective and with acomputerized system existing problems can be avoided and improve the way it works accurately.
\end{abstract}

\section{Keywords: Design, Application, Laundry}

\section{PENDAHULUAN}

Laundry atau binatu adalah proses pencucian suatu benda dengan jalan menghilangkan partikelpartikel atau pengotor yang tidak diinginkan dari benda tersebut sehingga diperoleh keadaan semula dari benda yang bersangkutan untuk mencapai tujuan yang diinginkan. Usaha jasa laundry pakaian semakin mudah ditemui pada banyak tempat mulai dari daerah perkotaan yang padat, perumahan, bahkan sampai masuk ke desa. Banyaknya jasa laundry dikarenakan terbatasnya waktu yang dimiliki untuk mencuci dan setrika pakaian, serta keinginan manusia untuk memperoleh segala sesuatu dengan cepat dan praktis. Tiavi Laundry adalah salah satu tempat usaha yang bergerak dibidang pelayanan jasa laundry yang masih melakukan proses pendataan yang masih manual. Sistem informasi adalah sebuah rangkaian prosedur formal dimana data dikelompokkan, diproses menjadi informasi, dan didistribusikan kepada pemakai (Yakub, 2012).Teknologi informasi memiliki hubungan yang sangat erat dengan sistem informasi yang merupakan suatu kumpulan komponen yang saling terintegrasi dalam proses pengolahan data melalui proses komputerisasi. Dalam proses pengolahan data menjadi diperlukan adanya alat bantu yang berupa aplikasi terkomputerisasi untuk memudahkan pengolahan data yang dibutuhkan, sehingga tidak membutuhkan waktu yang lama serta keamanan data dapat terjamin. Dengan adanya sistem yang baik maka aktivitas bisa terbantu serta dapat memudahkan dalam memberikan informasi yang baik.Tujuan penelitian pada artikel ini untuk memudahkan proses sistem pendataan usaha laundry secara terkomputerisasi dan menangani permasalahan yang ada, pembuatan aplikasi berbasis desktop meminimalisasi penggunaan kertas, aplikasi yang dapat digunakan untuk memudahkan usaha Tiavi Laundry dalam proses pendataan, penghitungan dan pembuatan laporan yang lebih efektif. Kegunaan penelitian ini diharapkan dapat memberikan manfaat yang baik bagi pihak-pihak 
yang terkait, terutama pada Tiavi Laundry agar menangani permasalahan pengolahan sistem pada Tiavi Laundry.

\section{PENELITAN RELEVAN}

Beberapa penelitian yang relevan antara lain (Haqi, 2018) dengan judul "Sistem Informasi Pelayanan Jasa Laundry Pada Fatma Fresh Berbasis Java Netbeans Dengan Menggunakan Scan Barcode Android". Penelitian tersebut bertujuan sebagai solusi pelayanan jasa di Fatma Fresh Laundry dalam pengelolaan data laundry, data pelanggan (member, non-member), data transaksi pelanggan (member, non-member) dan transaksi jasa laundry, serta penyajian laporan transaksi pelanggan (member, non-member), dan laporan keuangan laundry dengan baik.(Saputra sendi, 2018)menyimpulkan dengan aplikasi pada usaha laundry dapat memudahkan penginputan datadata berupa data pelanggan dan karyawan, memudahkan proses pencarian laporan, memudahkan dalam penghitungan biaya dan mengefesienkan waktu dan menjaga keamanan data. Penelitian selanjutnya oleh (Rachmatika \& Wulandari, 2019) dengan judul "Rancangan Aplikasi Laundry Berbasis Dekstop Pada Krisna Laundry Untuk Wilayah Limo". Tujuan penelitiannya adalah membuat Krisna Laundry menjadi lebih mudah dan efisien selain itu membuat keamanan yang terjaga.

\section{METODE PENELITIAN}

Metode penelitian pada dasarnya merupakan cara ilmiah untuk mendapatkan data dengan tujuan dan kegunaaan tertentu (Sugiyono, 2015). Metode penelitian yang digunakan yang adalah metode R\&D (Researchand Development) merupakan metode penelitian yang digunakan untuk menghasilkan produk tertentu dan menguji keefektifan produk tersebut (Sugiyono, 2013). Langkah-langkah dalam penelitian $R \& D$ adalah sebagai berikut: 1) Potensi dan masalah 2) Mengumpulkan informasi 3) Desain produk4) Validasi desain5) Perbaikan desain 6) Uji Coba produk 7) Revisi produk 8) Uji coba pemakaian 9) Revisi produk dan 10) Pembuatan produk masal.

Metode pengumpulan data yang dilakukan yaitu studi kepustakaan yaitu dengan mengumpulkan data dan informasi dari buku-buku, serta hasil penelitian bahan lainnya yang relevan. Wawancara dilakukan langsung dengan pemilik usaha laundry yang dijadikan objek penelitian yaitu dengan ibu Rahmawati. Metode observasi dengan peninjauan secara langsung di tempat penelitian, yaitu di Tiavi Laundry beralamat di jalan cilayu Rt 06 Rw 03 No 96 Kelurahan Cisalak Pasar Kecamatan Cimanggis Kota Depok.

\section{HASIL DAN PEMBAHASAN}

\section{Alternatif Penyelesaian Masalah}

Beberapa uraian masalah yang dihadapi dalam sistem pemrosesan data, penghitungan dan pembuatan laporan, maka peneliti memberi alternatif penyelesaian masalahnya, yaitu:

1. Aplikasi sistem informasi laundry yang terkomputerisasi sehingga dapat dihasilkan informasi yang lebih cepat, tepat dan akurat.

2. Perancangan database untuk sistem pengolahan data cucian atau laundry, data pelanggan sehingga penyimpanan data mudah untuk diolah kembali.

3. Proses segala penghitungan menjadi terkomputerisasi dan tersimpan dalam database.

4. Membuat aplikasi yang dapat mudah dipahami oleh setiap user agar dapat digunakan oleh setiap user, baik yang memahami dalam pengoperasian komputer maupun tidak.

\section{Data Flow Diagram atau (DFD)}

Data Flow Diagram (DFD) adalah suatu network yang menggambarkan suatu system automat komputerisasi, normalisasi, atau gabungan dari keduanya yang penggambarannya disusun dalam bentuk kumpulan komponen system yang saling berhubungan sesuai dalam bentuk kumpulan komponen system yang saling berhubungan sesuai dengan aturan mainnya (Sutabri, 2012). 


\section{Diagram Konteks Sistem yang Diusulkan}

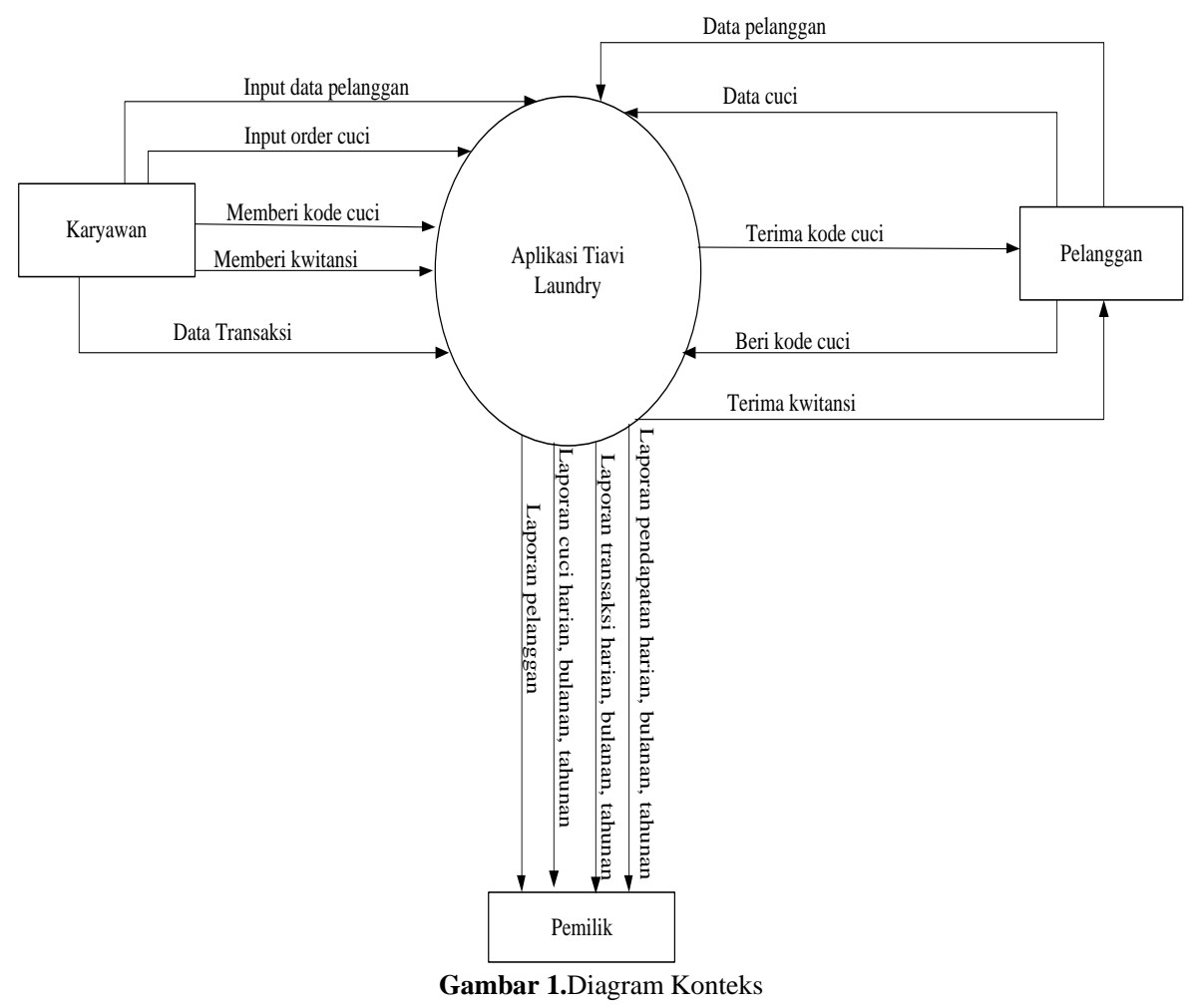

\section{Entity Relationship Diagram (ERD)}

ERD adalah suatu model untuk menjelaskan mengenai hubungan antar data dalam basis data berdasarkan objek-objek dasar data yang memiliki hubungan antar relasi. Entity Relationship Diagram untuk memodelkan struktur data serta hubungan antar data, untuk dapat menggambarkannya digunakan beberapa notasi serta simbol (Ibeng, 2018).

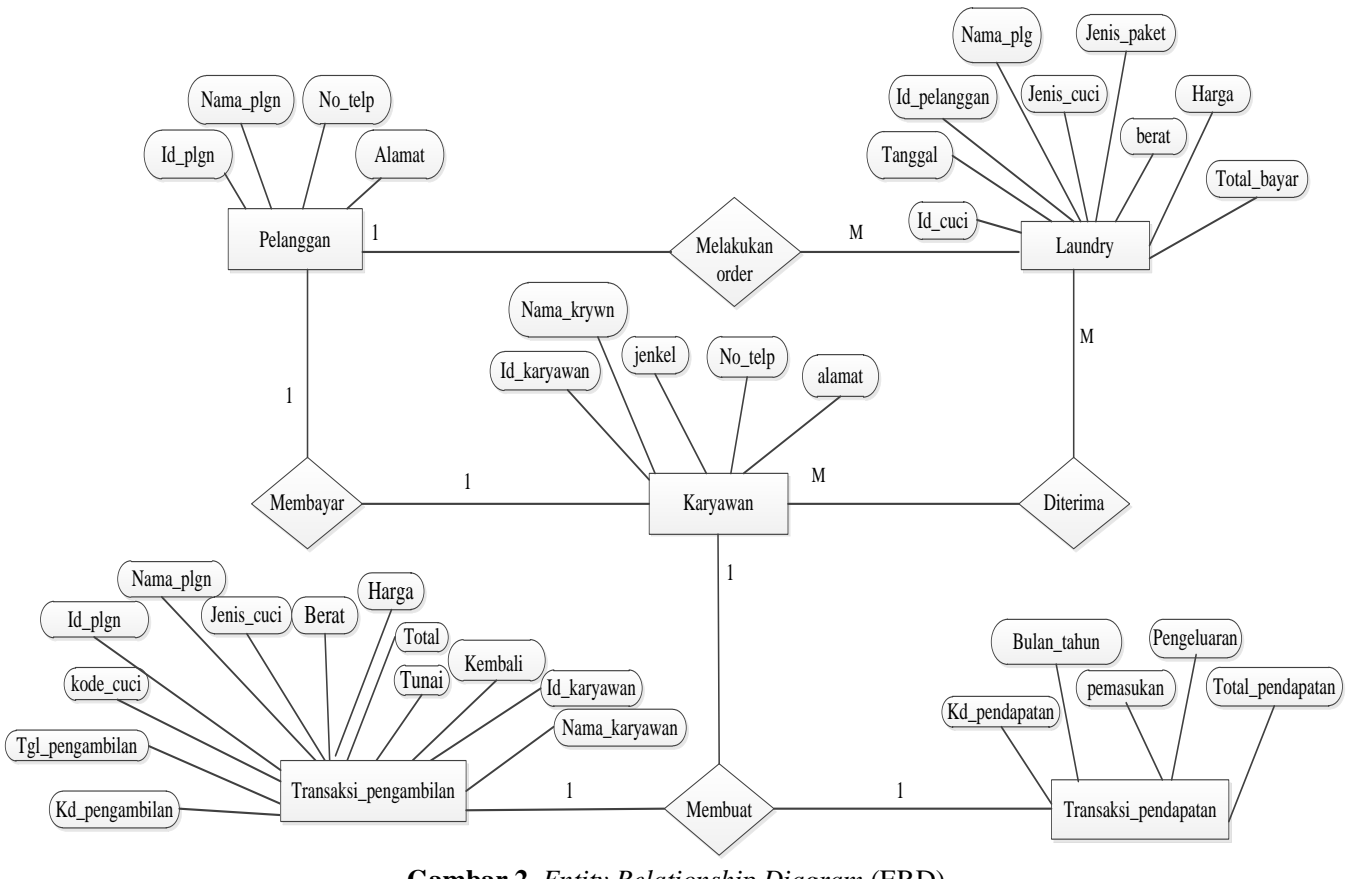

Gambar 2. Entity Relationship Diagram (ERD) 


\section{Tampilan Layar}

Berikut tahapan implementasi dan pengujian pada software program yang telah di buat dengan bahasa pemrograman java.

\section{Tampilan Layar Login}

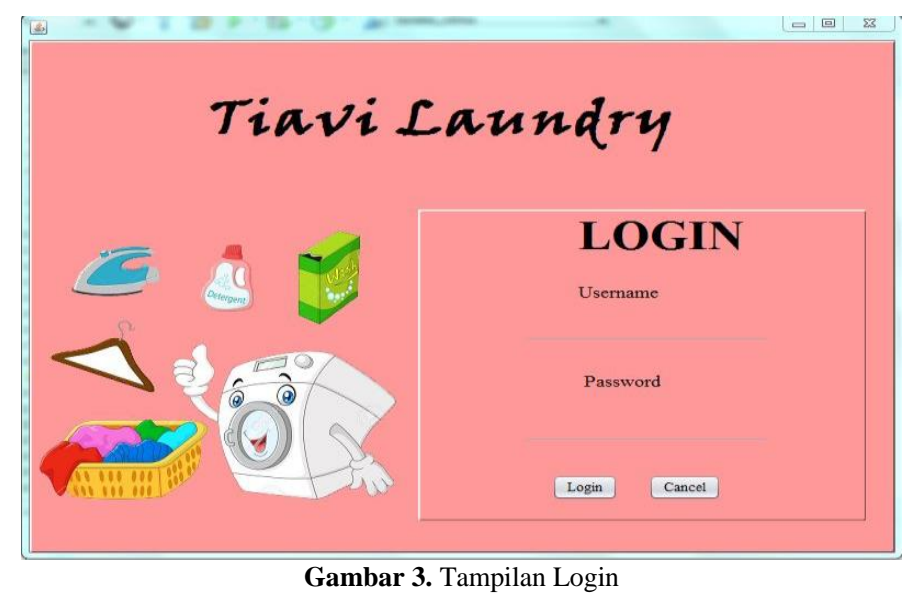

Tampilan login yaitu menu yang pertama kali tampil pada saat program dijalankan.Kasir memasukan username dan password, setelah berhasil login akan masuk tampilan halaman utama. Yang dapat menjalankan sistem hanyalah orang yang memiliki akses terhadap aplikasi laundry.

\section{Tampilan Layar Halaman Utama}

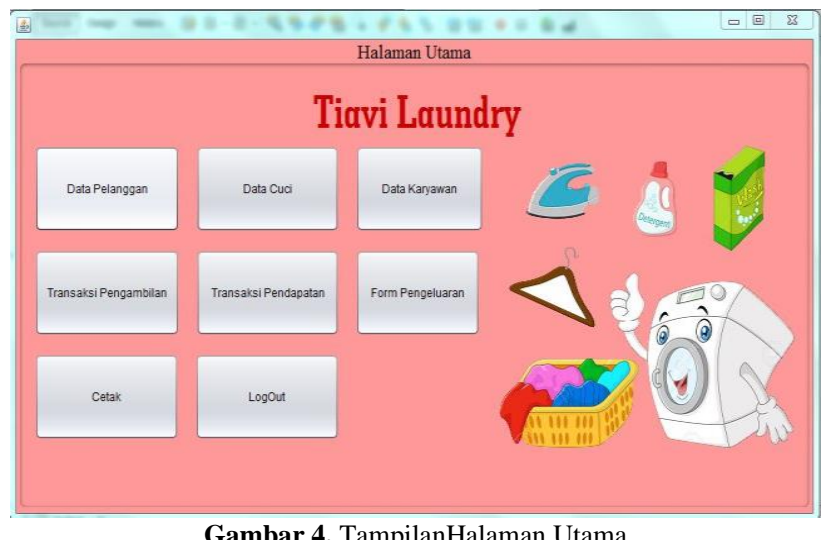

Pada tampilan halaman utamaadalah dasar program aplikasi laundry sebagai penunjang untuk mengakses menu-menu yang lainnya. Pada halaman menu utama terdapat menu data pelanggan, data cuci, data karyawan, transaksi pengambilan, transaksi pendapatan, form pengeluaran, menu cetak dan logout. 


\section{Tampilan Layar Menu Data Cuci}

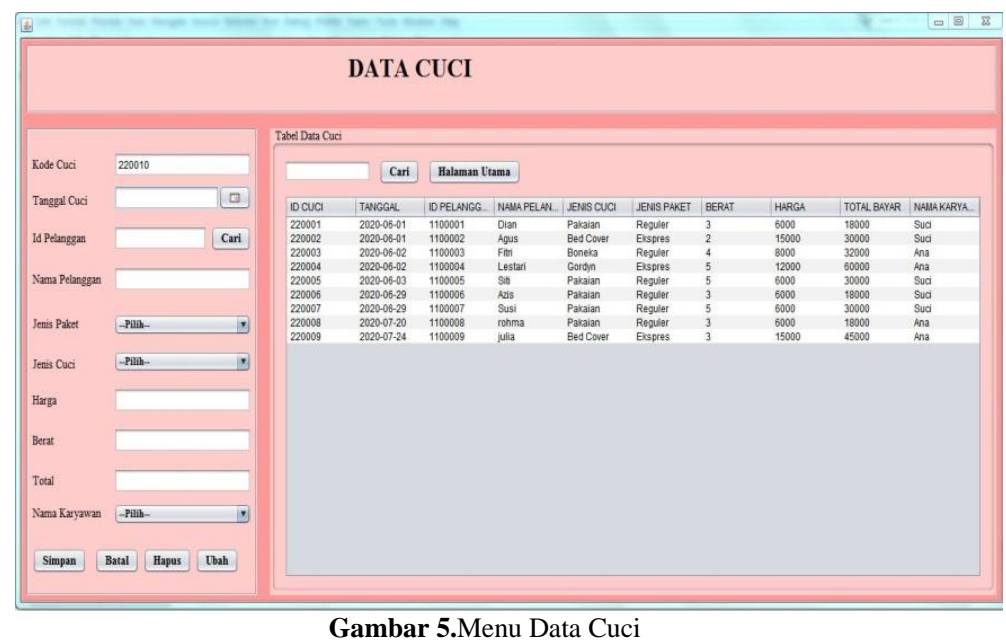

Tampilan menu data cuci (gambar 5) digunakan untuk melakukan pendataan order cucian setiap pelanggan yang datang ke tempat Tiavi Laundry. Data yang selesai diinput akan tersimpan ke database, data dapat diubah, hapus dan dapat mencari data cuci.

\section{Tampilan Layar Menu Transaksi Pendapatan}

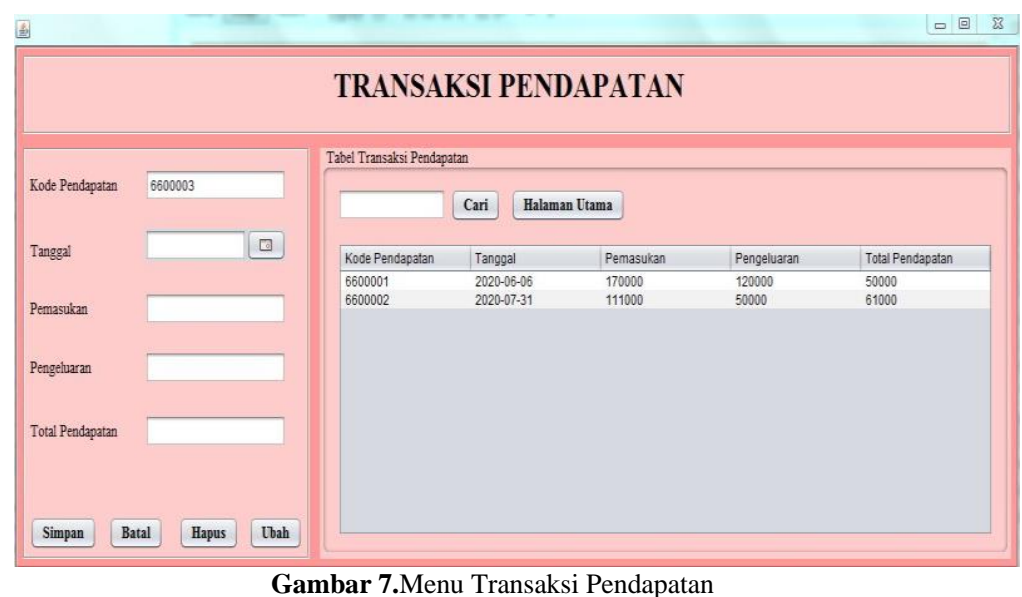

Tampilan menu transaksi digunakan untuk menghitung pemasukan dan pengeluaran yang ada pada Tiavi Laundry. 


\section{Tampilan Laporan Data Cucian}

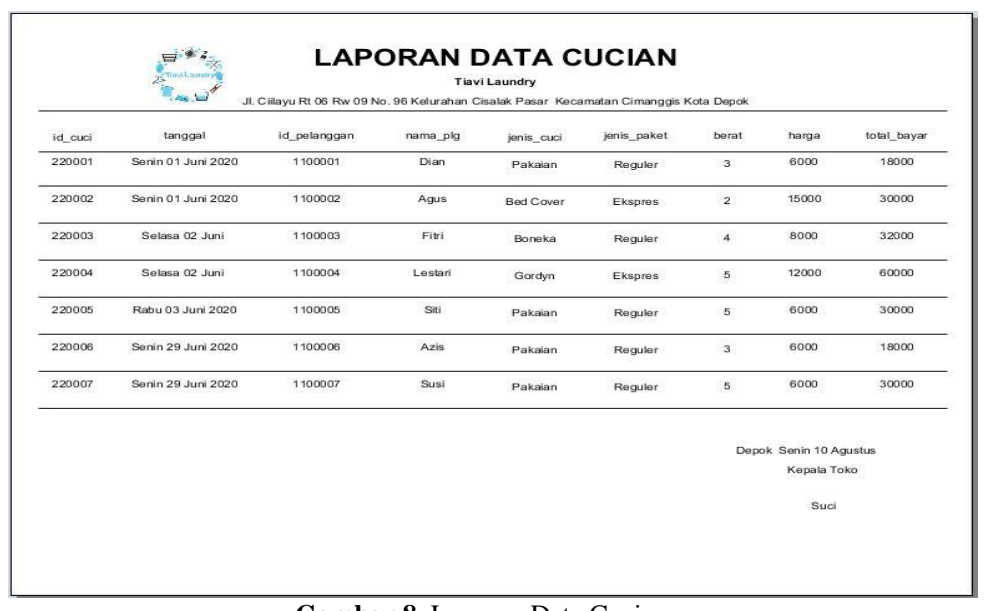

Gambar 8. Laporan Data Cuci

Tampilan laporan data cucian (gambar 8) merupakan hasil dari inputan data cuci (gambar 5), kemudian data tersebut dicetak lalu menghasilkan keluaran berupa laporan data cucian untuk diserahkan kepada pemilik sebagai arsip laundry.

\section{Tampilan Laporan Pendapatan}

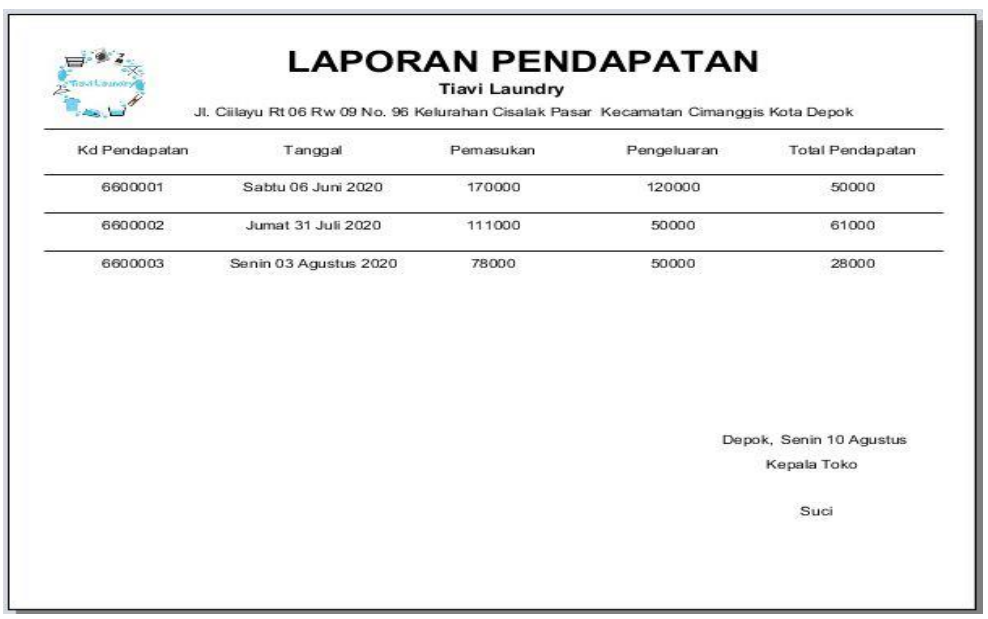

Gambar 7. Laporan Transaksi Pendapatan

Pada tampilan transaksi pendapatan digunakan untuk mengetahui total pendapatan pada TiaviLaundry.

\section{Pengujian Fungsional Perangkat Lunak}

Black box pengujian adalah metode pengujian perangkat lunak yang menguji fungsionalitas aplikasi yang bertentangan dengan struktur internal atau kerja. Pengujian black box sebagai berikut:

Tabel 1. Pengujian Data Cuci

\begin{tabular}{lllll}
\hline No & Rancangan Proses & Hasil Yang Diharapkan & Hasil & Keterangan \\
\hline 1 & $\begin{array}{l}\text { Login kasir } \\
2\end{array}$ & $\begin{array}{l}\text { Memilih menu data } \\
\text { cucian }\end{array}$ & Masuk ke halaman utama & Sesuai \\
\\
3 & Memilih simpan & Data tersimpan kedalam database & Sesuai & \\
4 & Memilih ubah & Data berhasil berubah & Sesuai \\
5 & Memilih hapus & Data berhasil terhapus & Sesuai \\
\hline
\end{tabular}




\begin{tabular}{llll}
\hline 6 & Memilih batal & $\begin{array}{l}\text { Menghilangkan data yang ada } \\
\text { dikolom input }\end{array}$ & Sesuai \\
7 & Memilih cari & Berhasil mencari data & Sesuai \\
8 & Memilih halaman utama & Kembali ke halaman utama & Sesuai \\
\hline
\end{tabular}

Tabel 2. Pengujian Transaksi Pendapatan

\begin{tabular}{lllll}
\hline No & Rancangan Proses & Hasil Yang Diharapkan & Hasil & Keterangan \\
\hline 1 & Login kasir & Masuk ke halaman utama & Sesuai & \\
2 & $\begin{array}{l}\text { Memilih menu transaksi } \\
\text { pendapatan }\end{array}$ & $\begin{array}{l}\text { Menampilkan form } \\
\text { transaksi pendapatan }\end{array}$ & Sesuai \\
3 & Memilih simpan & Data tersimpan kedalam database & Sesuai \\
4 & Memilih ubah & Data berhasil berubah & Sesuai \\
5 & Memilih hapus & Data berhasil terhapus & Sesuai \\
6 & Memilih batal & $\begin{array}{l}\text { Menghilangkan data yang ada } \\
\text { dikolom input Sesuai }\end{array}$ \\
7 & Memilih cari & Berhasil mencari data & Sesuai \\
8 & Memilih halaman utama & Kembali ke halaman utama & Sesuai \\
\hline
\end{tabular}

Hasil penelitian ini sejalan dengan(Zy, 2017) yang menyimpulkan bahwa suatu software dapat mengimput data konsumen dan cucian dengan tepat dan akurat, keamanan cucian. Pencarian data dan laporan menjadi lebih cepat dan efisien serta(Pipit, 2017) dengan kesimpulan bahwa proses penerimaan, pembayaran dan pembuatan laporan pada dan efisien hingga pada akhirnya meningkatkan kinerja pegawai.

\section{SIMPULAN}

Simpulan yang diperoleh dari pembuatan perancangan aplikasi pada Tiavi Laundry yaitu sistem yang ada pada Tiavi Laundry menjadi terkomputerisasi, rapih dalam hal penyimpanan data dan laporan, proses pendataan menjadi lebih mudah untuk karyawan dan pemilik. Aplikasi ini menjadikan setiap proses penghitungan yang tepat dan hanya membutuhkan waktu dalam hitungan detik saja, dengan sistem yang terkomputerisasi masalah yang ada dapat dihindari.

\section{DAFTAR PUSTAKA}

Haqi, B. (2018). Sistem Informasi Pelayanan Jasa Laundry pada Fatma Fresh Berbasis JAVA Netbeans dengan Mengunakan Scan Barcode Android. Prosiding Seminar Nasional Pendidikan KALUNI, 1(April), 150-156. https://doi.org/10.30998/prossnp.v1i0.35

Ibeng. (2018). Pengertian Entity Relationship Diagram (ERD). Www.pendidikanku.org, xii(33), 43.

Pipit, A. (2017). Perancangan Sistem Informasi Pelayanan Jasa Laundry Pada Go-Wash Laundry Bogor. AMIK BSI Bogor.

Rachmatika, R., \& Wulandari, R. D. (2019). Rancangan Aplikasi Laundry Berbasis Dekstop Pada Krisna Laundry Untuk Wilayah Limo Design of Laundry Application Based on Decstop on Krisna Laundry for Limo Areas. Prosiding Seminar Nasional Informatika Dan Sistem Informasi, 4(1), 46-53.

Saputra sendi. (2018). Aplikasi Naura Laundry Dengan Java Dan MySQL.

Sugiyono. (2013). Buku - Sugiyono. In Metode Penelitian Kuantitatif, Kualitatif, dan R \& D (p. 407).

Sugiyono. (2015). Metode Penelitian. Metode Penelitian.

Sutabri. (2012). Aplikasi Pengolahan Data Penawaran Pengadaan Barang Dan Jasa. Aplikasi, 1-14.

Yakub. (2012). Pengertian Sistem Informasi Menurut Ahli. 4 Januari, 3-5.

Zy, A. T. (2017). Sistem Informasi Laundry Pada Wawa Laundry Berbasis Web. Jurnal Teknologi Pelita Bangsa SIGMA, Vol.7,No.2. 